\title{
Contusion Index is an Important Tool for the Management of Traumatic Intracerebral Hematoma
}

\author{
Adnan Khaliq ${ }^{1}$ Mumtaz Ali² Farooq Azam $^{3} \quad$ Nayab Gul ${ }^{4} \quad$ Bipin Chaurasia ${ }^{5}$ \\ ${ }^{1}$ Department of Neurosurgery, Saidu Medical College/Saidu \\ Teaching Hospital, Swat, Pakistan \\ 2Prime Teaching Hospital, Peshawar Medical College, Peshawar, \\ Pakistan \\ ${ }^{3}$ Lady Reading Hospital Peshawar, Peshawar, Pakistan \\ ${ }^{4}$ Rehman Medical Institute, Peshawar, Pakistan \\ ${ }^{5}$ Neurosurgery Clinic, Birgunj, Nepal \\ Indian J Neurotrauma 2022;19:19-22. \\ Address for correspondence Adnan Khaliq, MBBS, FCPS, \\ Saidu Medical College/Saidu Teaching Hospital, Swat, Pakistan \\ (e-mail: dradnankhaliq@gmail.com).
}

\begin{abstract}
Keywords

- contusion index

- Glasgow Coma Scale

- head injury

- intracerebral

contusions

Objective This article evaluates outcome of traumatic intracerebral hematomas in terms of Glasgow Coma Scale (GCS) after medical or surgical management according to contusion index.

Materials and Methods This descriptive study was conducted in the Department of Neurosurgery, Lady Reading Hospital, Peshawar, Pakistan from January 2017 to December 2018. Total number of patients with traumatic intracerebral contusions included in this study was 60 with age between 5 and 75 years. Both male and female were included. Patients with other coexisting traumatic intracranial hematomas like extradural hematoma, subdural hematoma, and polytrauma were excluded from this study. Contusion index of patients were calculated by noncontrast-enhanced computed tomography brain. On arrival patient GCS was documented. The management protocol, that is, conservative or surgical, was provided to individual patient according to contusion index as calculated. Outcome of management was assessed in terms of GCS.

Results Patients with contusion index of 0 to 4 were managed conservatively. Patients with contusion index of 6 were offered surgical management. Patients with contusion index of 9 had poor outcome with both conservative and surgical management.

Conclusion Contusion index can be used reliably as a tool for management of isolated traumatic intracerebral hematomas
\end{abstract}

\section{Introduction}

Head injury is one of the leading causes of morbidity and mortality. The current reported mortality of traumatic brain injury is 40 per 100,000 annually. ${ }^{1}$ Head injury might result in extradural hematoma, subdural hematoma, subarachnoid hemorrhage, and intracerebral hematoma. Intracerebral hematoma is also called contusion. The vascularity of gray matter is more than white matter. Contusion primarily occur in superficial gray matter with secondary extension to deep white matter. ${ }^{2-5}$ Contusions can be unilateral or bilateral ranging from small petechial to large hematoma. Contusions are more common in frontal and temporal lobes because of interface with underlying bony projections. ${ }^{6}$ They are rarely seen in occipital and parietal lobes. Contusion results from coup or contrecoup impact to the head with differential published online

July 3, 2021
DOI https://doi.org/

10.1055/s-0041-1727293

ISSN 0973-0508
(C) 2021. Neurotrauma Society of India.

This is an open access article published by Thieme under the terms of the Creative Commons Attribution-NonDerivative-NonCommercial-License, permitting copying and reproduction so long as the original work is given appropriate credit. Contents may not be used for commercial purposes, or adapted, remixed, transformed or built upon. (https://creativecommons.org/licenses/by-nc-nd/4.0/).

Thieme Medical and Scientific Publishers Pvt. Ltd. A-12, 2nd Floor, Sector 2, Noida-201301 UP, India 
movement of brain within the skull and results in sliding of cortex along the inner rough surface of the skull. ${ }^{7-10}$ It is sometimes difficult for neurosurgeons to decide whether to perform conservative or surgical intervention, so a standard tool of measurement is required along with Glasgow Coma Scale (GCS) for more favorable results of a particular treatment. It has been mentioned to a limited level in international literature and no national and international studies have been done on contusion index. So the study will provide a guideline for practicing neurosurgeons. - Table $\mathbf{1}$ and -Figs. 1 and $\mathbf{2}$ give some idea of how we calculated contusion index.

\section{Methodology}

This descriptive study was conducted in the Department of Neurosurgery, Lady Reading Hospital, Peshawar, Pakistan from January 2017 to December 2018. Patients were assessed by history, neurological, and systemic examination for associated injuries and computed tomography (CT) brain. Total number of patients with traumatic intracerebral contusions included in this study was 60 with age ranges from 5 to 75 years. Both male and female were included in the study. Patients with other coexisting traumatic intracranial hematomas like extradural hematoma, subdural hematoma, intraventricular hemorrhage, and polytrauma were excluded

Table 1 Contusion index ${ }^{5}$

\begin{tabular}{|l|l|l|}
\hline Grade & Depth of contusion & Extent of contusion \\
\hline 0 & Absent & Absent \\
\hline 1 & $\begin{array}{l}\text { Affects half of the cortex of } \\
\text { brain }\end{array}$ & Localized \\
\hline 2 & $\begin{array}{l}\text { Affects full thickness of } \\
\text { cortex }\end{array}$ & Moderately extensive \\
\hline 3 & Extension to white matter & Extensive \\
\hline
\end{tabular}

Note: Contusion index is calculated as:

Depth of contusion $\times$ Extent of contusion $=$ Contusion index score $(0-9)$.

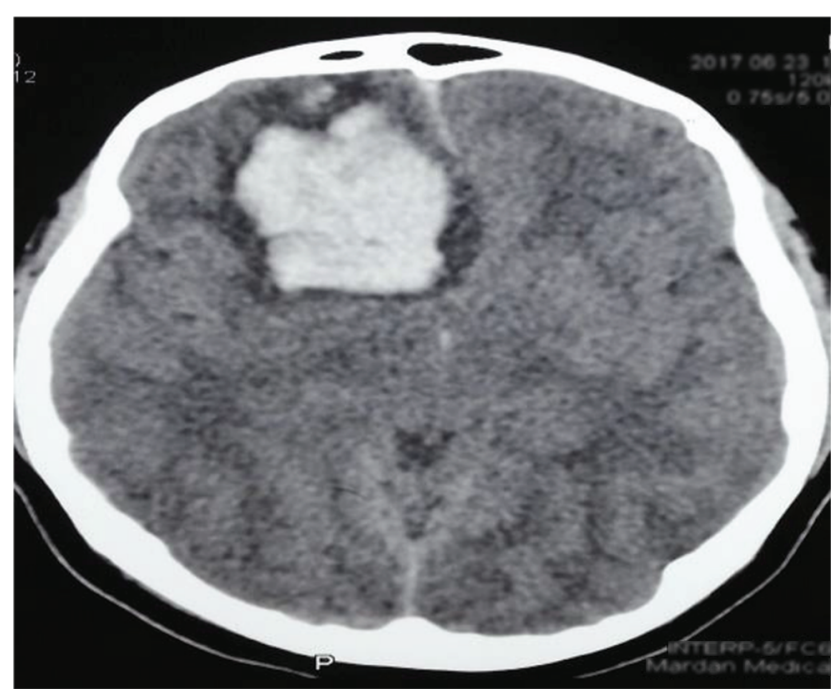

Fig. 1 Computed tomography (CT) brain with right frontal contusion with contusion index $=3 \times 3=9$.

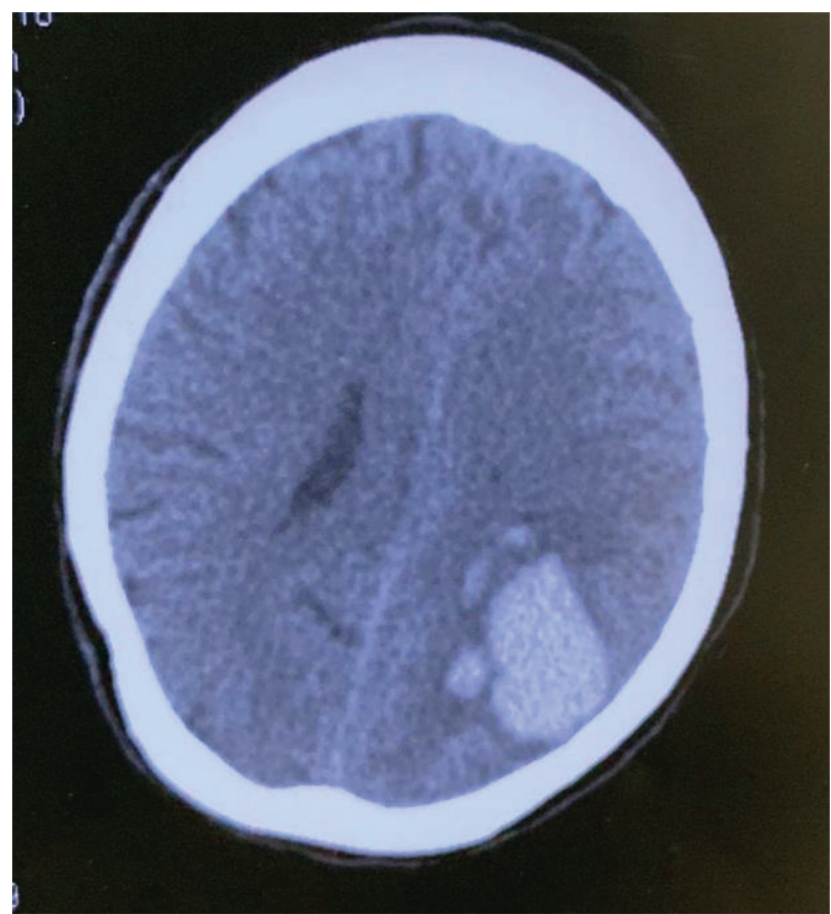

Fig. 2 Contusion index is $2.5 \times 3.0=7.5$.

from this study. Contusion index of patients was calculated by noncontrast-enhanced CT brain. On arrival patient GCS was documented. The management protocol, that is, conservative or surgical, was provided to individual patient according to contusion index as calculated. Outcome of management was assessed in terms of improvement in GCS. Patients with contusion index of 0 to 4 were treated conservatively. Patients with contusion index of 6 were treated surgically, and patients with contusion index of 9 were treated conservatively/surgically depending upon GCS. Some of the cases of contusions where we applied contusion index are shown in - Figs. 1 and 2.

\section{Results}

A total of 60 patients were diagnosed by CT brain as traumatic contusions. Out of these patients 3 patients had GCS of 15/15) and contusion index of 1 . Twelve patients had GCS of $14 / 15$ and contusion index of 2 and 7 patients had GCS $13 / 15$ and contusion index 3. All these patients with contusions index 1 to 3 were treated conservatively. Patients were given intravenous steroids, antiepileptics, intravenous fluids, and painkillers. On the third day of admission, all of the patients had GCS of 15/15 with slight hypodensity around contusions on serial CT brain. It shows that these patients had excellent recovery. Similarly, 14 patients had GCS of 11/15 and contusion index of 4 . These patients were operated and hematoma was evacuated with postoperative GCS of 15/15 in 11 patients and GCS of 13/15 in 3 patients, respectively, on the third postoperative day. So they had good recovery. In our study, 15 patients had GCS of 9/15 and contusion index of 6 . Patients were operated and evacuation of hematoma was done with postoperative GCS 
of $12 / 15$ on the third postoperative day in 13 patients. Two patients did not recover and died in intensive care unit (ICU). So these patients had satisfactory outcome. The last group of 9 patients had GCS less than 8 and contusion index of 9 . Out of these 9 patients, 5 were operated and 4 were managed conservatively in the ICU but all the patients died, so these patients had poor outcome. See - Tables 2-4 for details. - Table 5 is for Glasgow Outcome Scale extended score.

\section{Discussion}

In this study, we found that for patients with contusion index of 1 to 3 conservative management was good enough. It was noted that all these patients had GCS above 10/15.These patients survived and had excellent recovery with nonoperative treatment. Since there are no international studies available, therefore only one national study done on contusion

Table 2 Conservatively treated patients

\begin{tabular}{|l|l|l|l|l|}
\hline $\begin{array}{l}\text { No of } \\
\text { patients }\end{array}$ & $\begin{array}{l}\text { Contusion } \\
\text { index }\end{array}$ & $\begin{array}{l}\text { GCS at } \\
\text { day } \mathbf{1}\end{array}$ & $\begin{array}{l}\text { GCS at } \\
\text { day } 3\end{array}$ & Outcome \\
\hline 5 & 9 (Operated) & $7 / 15$ & $5 / 15$ & Died \\
\hline 4 & 9 (No surgery) & $5 / 15$ & $3 / 15$ & Died \\
\hline
\end{tabular}

Abbreviation: GCS, Glasgow Coma Scale.

Table 3 Conservative/surgically treated patients

\begin{tabular}{|l|l|l|l|l|}
\hline $\begin{array}{l}\text { No of } \\
\text { patients }\end{array}$ & $\begin{array}{l}\text { Contusion } \\
\text { index }\end{array}$ & $\begin{array}{l}\text { GCS at } \\
\text { day } \mathbf{1}\end{array}$ & $\begin{array}{l}\text { GCS at } \\
\text { day } 3\end{array}$ & Outcome \\
\hline 14 & 4 & $11 / 15$ & $15 / 15$ & Good recovery \\
\hline 15 & 6 & $9 / 15$ & $12 / 15$ & Delayed recovery \\
\hline
\end{tabular}

Abbreviation: GCS, Glasgow Coma Scale.

Table 4 Surgically treated patients

\begin{tabular}{|l|l|l|l|l|}
\hline $\begin{array}{l}\text { No of } \\
\text { patients }\end{array}$ & $\begin{array}{l}\text { Contusion } \\
\text { index }\end{array}$ & $\begin{array}{l}\text { GCS at } \\
\text { day } \mathbf{1}\end{array}$ & $\begin{array}{l}\text { GCS at } \\
\text { day } 3\end{array}$ & Outcome \\
\hline $3 / 60$ & 1 & $15 / 15$ & $15 / 15$ & Full recovery \\
\hline $12 / 60$ & 2 & $14 / 15$ & $15 / 15$ & Full recovery \\
\hline $7 / 60$ & 3 & $13 / 15$ & $13 / 15$ & Delayed recovery \\
\hline
\end{tabular}

Abbreviation: GCS, Glasgow Coma Scale.

Table 5 GOSE score

\begin{tabular}{|l|l|l|}
\hline GOSE & Category & $\begin{array}{l}\text { Frequency at } 6 \text { mo } \\
\text { (no of patients) }\end{array}$ \\
\hline 1 & Death & 9 \\
\hline 2 & Vegetative state & 0 \\
\hline 3 & Severe disability lower & 0 \\
\hline 4 & Severe disability upper & 2 \\
\hline 5 & Moderate disability lower & 7 \\
\hline 6 & Moderate disability upper & 15 \\
\hline 7 & Good recovery lower & 12 \\
\hline 8 & Good recovery upper & 15 \\
\hline
\end{tabular}

Abbreviation: GOSE, Glasgow Outcome Scale extended. index has same results as mentioned in our study. ${ }^{11}$ Much larger studies are therefore necessary to take into account the different aspects of our study before a definitive management protocol can be laid down on the basis of contusion index.

Similarly, group 2 of our study included 29 patients with contusion index of 4 to 6 . All of these patients had GCS more than 8 and were operated. Patients were subjected to craniotomy with evacuation of hematoma and water tight closure of dura. Postoperatively, patients were kept in ICU with regular observation of vitals and GCS. All of these patients survived and had good recovery. So the above results again favor the initial surgical management in patients with contusion index of 4 to 6 . Again, this is all an observation from our study and as this is a descriptive study and we do not have any previous studies relating contusion index to GCS on the basis of surgical versus conservative management, we cannot compare our results with any other studies.

The third group of patients had contusion index of 9. Of the 9 patients in the group, 5 had a good GCS (7/15) so they were operated with the hope to give them a chance for survival. But all these patients were on ventilators for many days in ICU and died later. Similarly, 4 patients with contusion index 9 were treated conservatively in the ICU. They had GCS of 5/15 on presentation. They keep on deteriorating in spite of best possible conservative treatment and died later on. This was in accordance with one local study done on contusion index showing same results. ${ }^{12,13}$ Our study design was descriptive and since no such work has been done in the past to determine any relationship between contusion index and GCS on the basis of conservative or surgical management we cannot give a definitive management protocol. We have simply stated what our results revealed. This study has, in no doubt, provided a framework for further studies in this context and is also free for criticism on how it could have been improved. The main purpose is to provide a framework for future studies for patients with contusions based on contusion index. This is very important because this will help the on-call neurosurgeon to arrive at a decision regarding conservative versus surgical management of patients with cerebral contusions based on contusion index and will also help to avoid unnecessary surgeries or vice versa.

There are many prognostic factors associated with outcomes after traumatic brain injury like GCS on admission, motor score, mid-line shift on CT scan, pupil response, subdural hematoma, gender, and intraventricular hemorrhage. We evaluated the outcome in the basis of contusion index for all patients.

\section{Conclusion}

In our conclusion we can say that patients with contusion index of 1 to 3 should be conservatively managed. Patients with contusion index of 4 to 6 should be operated. Patients with contusion index of 9 , no matter what, always showed a poor outcome. In our study there was $100 \%$ mortality in this group. 


\section{Conflict of Interest}

None declared.

\section{References}

1 Adams JH, Scott G, Parker LS, Graham DI, Doyle D. The contusion index: a quantitative approach to cerebral contusions in head injury. Neuropathol Appl Neurobiol 1980;6(4):319-324

2 Han JS, Kaufman B, Alfidi RJ, et al. Head trauma evaluated by magnetic resonance and computed tomography: a comparison. Radiology 1984;150(1):71-77

3 Marshall LF, Klauber MR. The outcome of severe closed head injury. J Neurosurg 1991;75:28-36

4 Kraus JF, Epidemiology of head injury. In: Copper PR, Ed. Head Injury. 2nd ed. Baltimore: Williams \& Wilkins; 1987:1-19

5 Macpherson BC, MacPherson P, Jennett B. CT evidence of intracranial contusion and haematoma in relation to the presence, site and type of skull fracture. Clin Radiol 1990;42(5):321-326

6 Adams JH, The neuropathology of head injuries. In: Vinkemn PJ, Bruyn GH, eds. Handbook of Clinical Neurology. Vol. 23. Amsterdam: North Holland; 1975:35-65
7 GudemanSK, Kishore PR,Becker DP, etal.Computed tomography in the evaluation of incidence and significance of post-traumatic hydrocephalus. Radiology 1981;141(2):397-402

8 Boom WH, Tuazon CU. Successful treatment of multiple brain abscesses with antibiotics alone. Rev Infect Dis 1985;7(2): 189-199

9 Illingworth RD, Operative surgery. Greensberg Handbook of Neurosurgery, 8th ed: 270-272

10 Stein SC, Ross SE. Moderate head injury: a guide to initial management. J Neurosurg 1992;77(4):562-564

11 Jennett B, Teasdale G, Galbraith S, et al. Severe head injuries in three countries. J Neurol Neurosurg Psychiatry 1977;40(3): 291-298

12 Temkin NR, Dikmen SS, Wilensky AJ, Keihm J, Chabal S, Winn HR. A randomized, double-blind study of phenytoin for the prevention of post-traumatic seizures. N Engl J Med 1990; 323(8):497-502

13 Narayan RK, Greenberg RP, Miller JD, et al. Improved confidence of outcome prediction in severe head injury. A comparative analysis of the clinical examination, multimodality evoked potentials, CT scanning, and intracranial pressure. J Neurosurg 1981;54(6):751-762 